\title{
Msx homeobox gene family and craniofacial development
}

\author{
Sylvia ALAPPAT ${ }^{1}, Z_{\text {Un }}$ Yi ZHANG ${ }^{1}$, Yi Ping CHEN ${ }^{1,2 *}$ \\ ${ }^{1}$ Division of Developmental Biology, Department of Cell and Molecular Biology, Tulane University, New orleans, \\ LA 70118,USA.E-mail: ychen@tulane.edu \\ ${ }^{2}$ College of Bioengineering, Fujian Normal University, Fuzhou, Fujian Province, China
}

\begin{abstract}
Vertebrate Msx genes are unlinked, homeobox-containing genes that bear homology to the Drosophila muscle segment homeobox gene. These genes are expressed at multiple sites of tissue-tissue interactions during vertebrate embryonic development. Inductive interactions mediated by the $M s x$ genes are essential for normal craniofacial, limb and ectodermal organ morphogenesis, and are also essential to survival in mice, as manifested by the phenotypic abnormalities shown in knockout mice and in humans. This review summarizes studies on the expression, regulation, and functional analysis of $M s x$ genes that bear relevance to craniofacial development in humans and mice.
\end{abstract}

Key words: Msx genes, craniofacial, tooth, cleft palate, suture, development, transcription factor, signaling molecule.

\section{INTRODUCTION}

Vertebrate craniofacial organs form from multiple embryonic tissues including the cranial neural crest derived cells, prechordal mesoderm, and the embryonic craniofacial ectoderm. Normal craniofacial morphology develops as a consequence of complex interactions between these embryonic tissues, and requires precise regulation of cell movement, growth, patterning, and differentiation of craniofacial tissues. Genetic studies have revealed the involvement of numerous genes in these processes, including genes encoding a variety of transcription factors, growth factors and receptors[1]. Mutations in genes that influence any of these processes would cause craniofacial abnormalities, such as facial clefting and craniosynostosis, which are among the most frequent congenital birth defects in humans[2]. Among the critical factors involved in craniofacial development are members of the Msx homeobox gene family. The vertebrate $M s x$ genes were initially cloned from mice and identified as homologous to the Drosophila muscle segment homeobox gene $(m s h)[3,4]$. Subsequently,

Correspondence a YI PING CHEN

Department of Cell and Molecular Biology, Tulane University, New Orleans, LA 70118, USA Tel: 504-865-5587; Fax: 504-865-6785

E-mail: ychen@tulane.edu
Msx genes have been isolated from a variety of organisms, including ascidians [5, 6], sea urchin[7], zebrafish [5, 8], frogs[9], birds[10-12], and humans[13]. The mammalian Msx gene family consists of 3 physically unlinked members, named $M s x 1, M s \times 2$, and $M s \times 3[14$, 15]. Msx 3 is only expressed in the dorsal neural tube, in a pattern resembling that of the prototypical Drosophila $m s h$ gene[16, 17]. However, in developing vertebrate embryos, $M s x 1$ and $M s x 2$ are widely expressed in many organs; particularly at the sites where epithelialmesenchymal interactions take place[15]. Most notably, $M s x 1$ and $M s x 2$ are strongly expressed in the developing craniofacial regions in an overlapping manner to some extent, indicating a role for $M s x$ genes in craniofacial development[18-21].

\section{Craniofacial morphogenesis}

During embryonic development, the face and neck are derived from swellings or buds of embryonic tissue, the branchial arches that originate bilaterally on the head. The neural crest cells generate most of the skeletal and connective tissue structures of the craniofacial region, while the mesoderm forms the musculature and endothelial lining of arteries of the future face and neck. The establishment of pattern in the craniofacial region is partly determined by the axial origin of the neural crest 
cells within each arch and partly by regional epithelialmesenchymal interactions[22,23]. In the mouse embryo, cranial neural crest cells originate from the posterior midbrain-hindbrain regions and migrate ventrolaterally into the branchial arches[24-28]. Within the branchial arches, the different populations of crest cells do not intermingle, but instead maintain the positional cues acquired by their rostral-caudal origins in the brain. This segregation of crest cell populations is established early in organogenesis by the apoptotic elimination of crest cells from specific levels of the hindbrain, giving rise to three distinct streams of migratory crest cells. Although this patterning of crest cells depends upon their rostralcaudal origin, this pattern does show some level of plasticity[29-31]. For example, the knockout of Hoxa-2 in mice caused the second arch to produce skeletal elements normally found in the first arch. This result suggests that the Hox genes can specify pattern in arches caudal to the first arch, which does not express this class of genes[32]. Further patterning of the crest cells within the arches involves a reciprocal series of epithelialmesenchymal interactions mediated by several growth factor signaling pathways[33-38].

The mammalian face develops from the coordinated growth and differentiation of five facial primordia, the single medial frontonasal prominence, the paired maxillary prominences, and paired mandibular prominences, which are located around the primitive mouth or stomodeum, as illustrated in Fig 1a and 1b. As development proceeds in the frontonasal prominence, localized thickenings of the surface ectoderm called nasal placodes develop. These placodes invaginate, while their margins thicken, to form the nasal pits and the lateral and medial nasal prominences. The maxillary prominences of the first branchial arch grow toward the future midline of the face. They fuse with the lateral nasal prominence on each side, then fuse with the medial nasal prominences, and finally with the intermaxillary segment of the frontonasal process to form the upper jaw and lip. In a similar way, the paired mandibular primordia fuse along their medial edge to form the lower jaw and lip. The frontonasal prominence forms the forehead and nose. Fusion of these approaching primordia results in the formation of a bilateral epithelial seam, which is later replaced by connective tissue[39-41] giving rise to a confluent lip. Clefts of the upper lip occur as a result of the failure of the maxillary prominence to merge with the medial nasal prominences on one side (producing a unilateral cleft) or on both sides (producing bilateral clefts). Failure of fusion of the paired mandibular prominences occurs far less frequently and results in clefts of the lower lip and jaw[42].

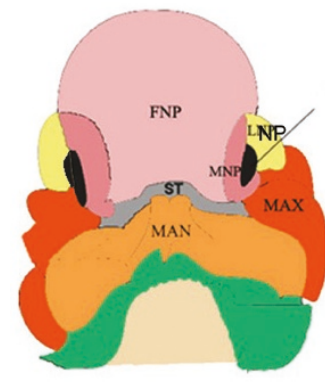

a

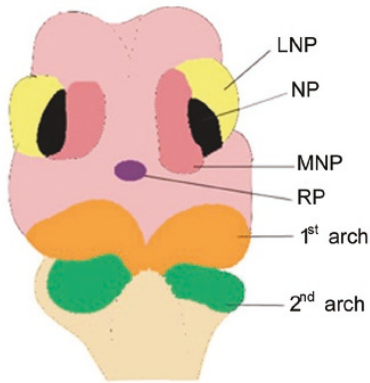

b
Fig 1. A schematic of the developing face in human and mouse embryos. (a) Frontal view of a head from a 37-day-old human embryo. (b) Frontal view of a head from a E10.5 mouse embryo. The medial frontonasal prominence (FNP, shown in light pink), the paired maxillary prominences (MAX, shown in red) and the paired mandibular prominences (MAN, shown in orange) constitute the five facial primordia that surround the primitive oral cavity, the stomodeum (ST, shown in grey). The nasal pits (NP, shown in black) are flanked by the lateral and medial nasal prominences (LNP in yellow and MNP in dark pink) which originate as placodes in the frontonasal prominence. The second branchial arch is indicated in green. RP, entrance to Rathke's pouch shown in magenta.
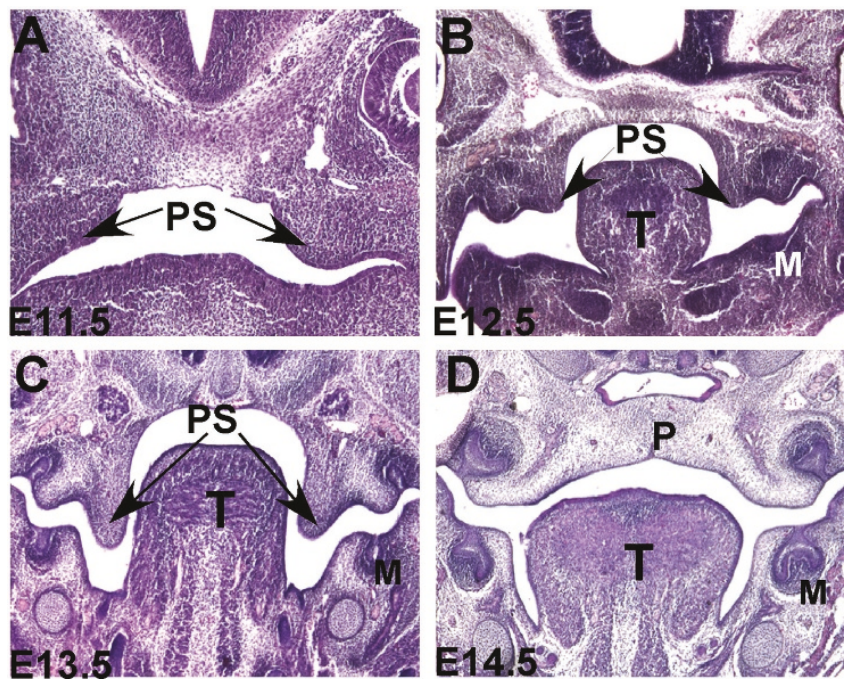

Fig 2. Histological sections of the mouse embryonic head showing representative stages of the developing secondary palate. (A) Frontal view of an E11.5 head showing bilateral palatal shelves projecting internally from the maxillary primordial. (B and $\mathbf{C}$ ) the paired palatal shelves at E12.5 (B) and E13.5 (C) are vertically oriented on either side of the tongue. (D) At E14.5 the shelves are horizontally oriented above the dorsum of the tongue and are fused medially to form a closed palate. Abbreviations: M, molar tooth bud; P, palate; PS, palatal shelf; $\mathrm{T}$, tongue. 
Craniofacial morphogenesis continues with the outgrowth and fusion of tissues that form the palate or the roof of the mouth. The palate forms from two primordia, the primary palate and the secondary palate. A single, median, wedge-shaped mass of mesenchyme extending internally from the frontonasal prominence forms the primary palate. The secondary palate develops bilaterally as two vertical projections, the palatal shelves, from the internal surfaces of the maxillary prominences (Fig 2). As morphogenesis proceeds, the shelves become oriented horizontally allowing them to approach each other and fuse medially. Failure of the palatal shelves to fuse leads to a cleft palate. A number of human congenital syndromes such as Treacher Collins Syndrome and Pierre Robin Syndrome have accompanying craniofacial abnormalities, which include a cleft palate[43]. Misregulation of the timing, rate, or extent of outgrowth of the palatal shelves results in clefts of the palate[44, 45]. Failure of fusion of the palatal shelves often, though not always, occurs in conjunction with cleft lip[46].

Another important morphogenetic event in the facial tissues is odontogenesis and this phase of craniofacial morphogenesis has been extensively studied. Tooth formation is regulated by inductive tissue interactions between the oral epithelium and the subjacent mesenchyme of the first arch. The four histologically distinct stages of tooth development are: 1) the dental lamina, 2) the bud, 3) the cap, and 4) the bell stage (Fig 3)[47]. In the mouse, tooth initiation becomes morphologically distinguishable at E11.5 by the thickening of the dental epithelium to form the dental lamina at the prospective sites of tooth formation. The cells of the dental lamina proliferate and on E12.5, start to invaginate into the underlying mesenchyme. At the bud stage, the mesenchyme proliferates and condenses around the invaginating epithelial bud. As a result of differential proliferation, the dental epithelium next convolutes around the condensed mesenchyme (now referred to as the dental papilla) in the cap (E14.5) and bell stages (E16.5). E14. 5 marks the onset of the definitive stages of tooth morphogenesis. In the cap and bell stages, transient signaling centers called primary and secondary enamel knots develop in the epithelium. They serve as organizing centers of tooth morphogenesis and cusp formation. In the final steps of odontogenesis, enamel-secreting ameloblasts and dentin-secreting odontoblasts differentiate from the dental epithelium and mesenchyme, respectively. Thus, an intricate set of epithelialmesenchy- mal interactions generates the species-specific pattern of odontogenesis.

Another craniofacial structure pertinent to our discussion on Msx genes is the skull. The skull (Fig 4) is a composite of multiple bones that are organized primarily into the neurocranium which includes the cranial vault and the viscerocranium that comprise the facial bones as well as the palatal, pharyngeal, temporal and auditory bones. The neurocranium whose function is to protect the brain and the sense organs derives from mesenchyme of both neural crest and mesodermal origin. The viscer-

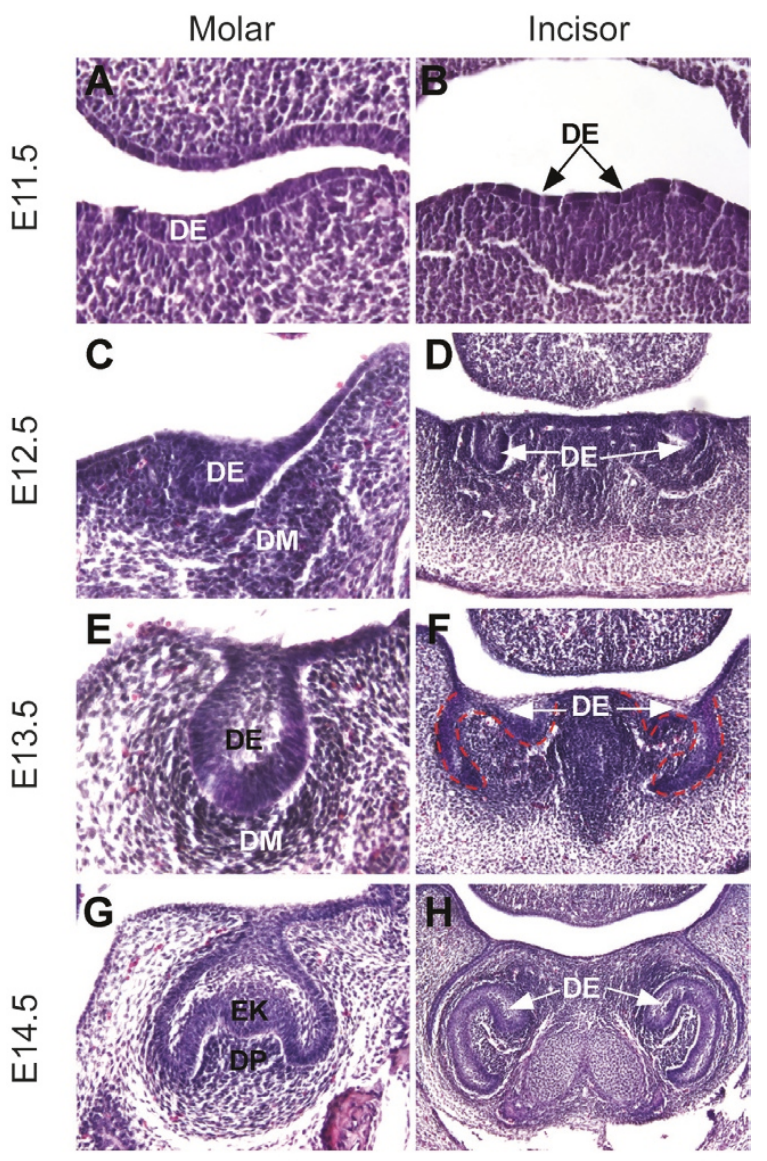

Fig 3. The representative stages of early tooth development in the mouse embryo. (A, C, E, G) molar tooth germ stages; (B, D, F, H) incisor tooth germ stages. (A and B) Dental lamina stage (E11.5): the oral epithelium thickens locally to form the molar and incisor tooth germs. (C and D) Early bud stage (E12.5): the epithelial thickening invaginates into the subjacent mesenchyme which condenses around the epithelial bud. (E and F) Late bud stage (E13.5): increased proliferation of the dental epithelium causes it to invaginate further into the dental mesenchyme; (G and $\mathbf{H})$ Cap stage (E14.5): differential proliferation within the dental epithelium causes a population of the dental mesenchyme, the dental papilla, to be surrounded by the convoluting dental epithelium. Abbreviations: DE, dental epithelium; DM, dental mesenchyme; DP, dental papilla; EK, enamel knot. 
ocranium by contrast is formed solely from neural crest mesenchyme. The calvaria or skull vault is formed by intramembraneous ossification of radially growing, discrete, mesenchymal condensates over the expanding brain. Fibrous, non-osteogenic membranes called sutures or fontanelles (wider sutures occurring at the juncture of several bones) separate the resulting calvarial bones formed by accretion growth. Further growth of the skull occurs by apposition at the lateral edges of the sutures, which are populated by highly proliferative preosteoblasts. Such a mechanism accommodates the constantly expanding brain. Unlike the skull vault, the base of the skull develops by endochondral ossification of the cartilaginous chondrocranium. Failures of inception, nonsynchronized growth or untimely ossification are some of the mechanisms contributing to dysmorphic development of the skull. The contribution of Msx genes in maintaining the delicate balance between proliferation and differentiation during pre- and post-natal skull morphogenesis will be elaborated upon later in this review.

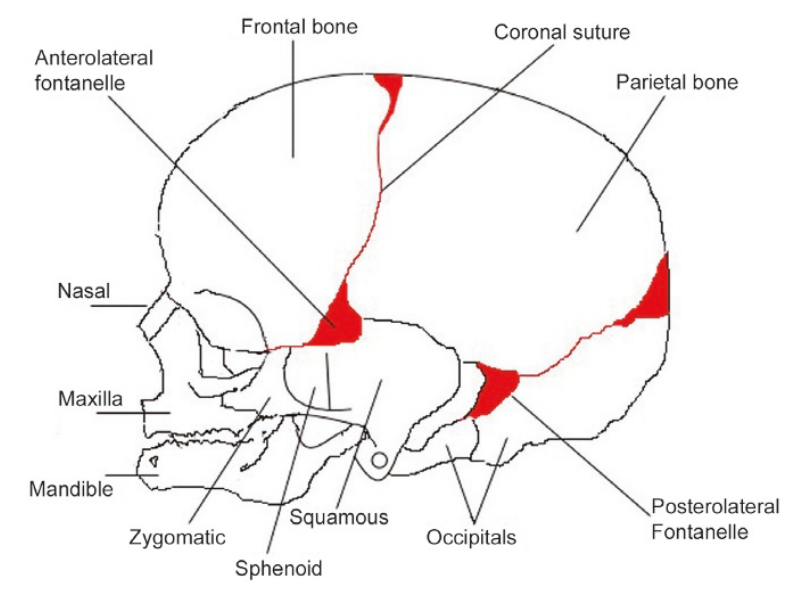

Fig 4. A schematic of the human skull showing the calvarial bones, fontanelles and sutures.

\section{Msx genes encode transcription repressors}

The Msx proteins are important modulators of craniofacial, limb, and nervous system development[16, $48,49]$. They are regulatory proteins that function as transcriptional repressors in vitro and in vivo[48, 5055]. Protein-protein interactions, which engage residues within their homeodomain guide target gene selection and transcription regulation[53, 54]. The Msx homeodomain interacts directly with the TATA binding protein (TBP), the core component of the general transcription complex to execute transcription repression.
Importantly, this ability to interact with members of the basal transcription machinery and affect transcription is not contingent upon their DNA-binding function[51]. Msx proteins also interact with other homeodomain proteins to regulate transcription. Heterodimers formed between $M s x 1$ and other homeodomain proteins such as $D l x 2, D l x 5, L h x 2$ and $P a x 3$ result in mutual functional antagonism in vitro [55-57]. It is believed that tissues in which expression of $M s x l$ overlaps these other proteins there may be such a regulatory mechanism in place. Although, both Msx1 and Msx2 show similar DNAbinding site preference as well as the ability to repress transcription they display different biochemical properties by virtue of unique $\mathrm{N}$-terminal domains, which confer Msx2 with a greater affinity for DNA while rendering Msx1 a more potent repressor. A study of the three dimensional structure of Msx 1 homeodomain/DNA complex reveals two major deviations from that of other homeodomain/DNA complexes[58]. Firstly, the presence of two non-canonical proline residues confers great stability and order to the N-terminal arm of the homeodomain, which tracks the minor groove of the DNA. Secondly, the DNA bound by the Msx1 homeodomain shows a $28^{\circ}$ bend compared to the normal $21^{\circ}$ observed with other homeodomain proteins.

\section{Expression of Msx genes during craniofacial development}

Overlapping expression of Msx 1 and Msx 2 are seen at multiple sites of tissue-tissue interaction including the craniofacial regions $[20,48,59]$. Through the course of murine craniofacial development, both $M s x 1$ and $M s x 2$ are detected in the forming skull and meninges, the distal aspects of the facial primordia, the associated sense organs, and teeth[18-20]. In the developing skull, Msx I and $M s x 2$ are expressed in the suture mesenchyme and dura mater. While Msxl expression extends into the postnatal stages of skull morphogenesis, Msx2 registers a sharp decline in expression after birth.

The earliest restricted distribution of $M s x l$ during tooth development is evident around E11.0 in the dental mesenchyme at the lamina stage, and the expression increases in the condensing dental mesenchyme at the bud stage (Fig 5). At the morphogenetic cap stages both the dental papilla and follicle express Msxl maximally. The expression begins to level off prior to the differentiation of the odontoblasts and ameloblasts. In the late stages of tooth morphogenesis, Msxl expression 
is clearly absent from the root sheath epithelium and is rather weak in the dental pulp[60]. By extrapolation, it appears that Msx 1 does not support root morphogenesis in the developing tooth. Apart from the tooth, Msx 1 expression has been examined in the developing palate. Reports of a weak, diffuse expression of Msxl in the palatal mesenchyme provided the first evidence that Msx 1 may have a direct role in palate development[18, 61]. A more detailed analysis by Zhang et al[62] has reported that Msxl expression in the palatal mesenchyme is confined to the anterior portion of the developing palatal shelves.

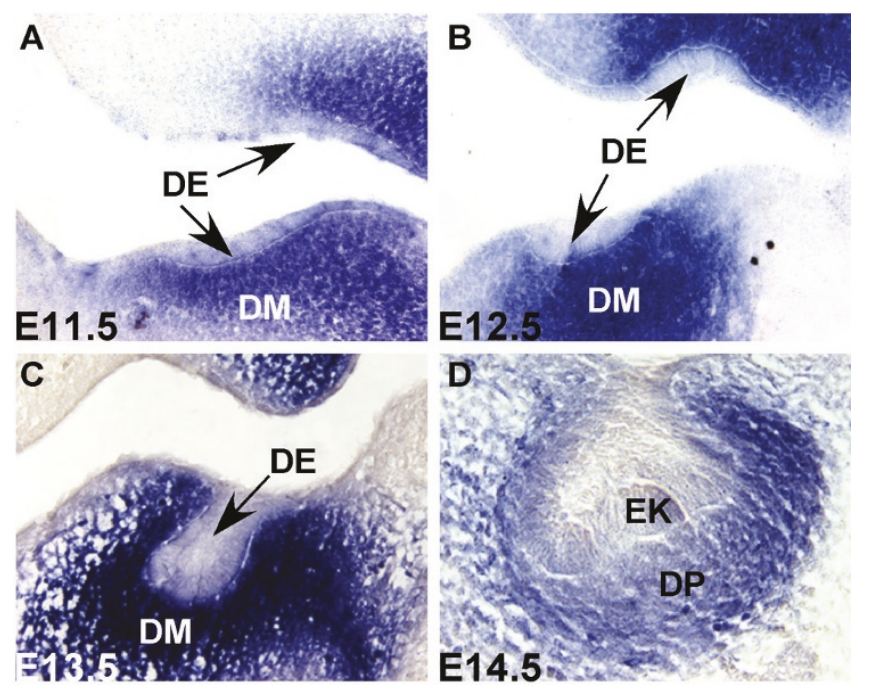

Fig 5. Murine $M s x 1$ expression in the early molar germs. Msx 1 expression is confined to the dental mesenchyme at E11.5 (A), E12.5 (B), E13.5 (C) and E14.5 (D). Maximal expression is seen at the bud stages E12.5 and E13.5. Abbreviations: DE, dental epithelium; DM, dental mesenchyme, DP, dental papilla; EK, enamel knot.

MSX2 expression is detectable by 7.5 weeks of human embryonic development[63]. In humans, the precursors of the orofacial skeleton such as the mandibular and maxillary bones, Meckle's cartilage, and tooth germs all express $M S X 2$ [63]. At the bud stage of developing tooth germ, MSX2 is detectable in the vestibular lamina, and both the dental epithelium and mesenchyme. Later in development, MSX2 expression is lost from the dental mesenchyme but is seen in the enamel knot and vestibular epithelium of the cap stage tooth. In mice, $M s x 2$ expression is continuous in the molar and incisor tooth germs $[20,61]$. Unlike the developing incisors, the molar tooth germs show asymmetric distribution of Msx2 at all developmental stages. Contrary to $M s x 1$, whose expre- ssion is confined to the mesenchyme throughout tooth development, $M s \times 2$ expression can be detected in both the epithelial and mesenchymal compartments of the developing tooth germs. The earliest indication of asymmetric expression is its buccal distribution seen within the invaginating dental lamina of molar tooth germs. At the cap stage, $M s x 2$ expression is prominently seen in the components of the enamel organ (the enamel navel, septum and knot) as well as the inner enamel epithelium. With the onset of the bell stage, Msx 2 expression is lost from the inner enamel epithelium as they differentiate into the ameloblasts. Instead, strong expression of $M s \times 2$ is detected in the odontoblasts and the subondontoblastic regions of the dental papilla. Thus, the spatial and temporal expression of $M s x 1$ and $M s x 2$ genes appear to correlate with crucial aspects of craniofacial morphogenesis. In the next section we will consider the molecular hierarchy controlling their expression as well as their role in craniofacial patterning.

\section{Regulation of Msx 1 and Msx2 expression and facial patterning}

The regulation of Msx gene expression is accomplished by diverse mechanisms involving retinoids, antisense 'quenching', growth factor regulation, and complementary/antagonistic interaction with other transcription factors. Retinoid regulation of $M s x$ genes was speculated following the identification of a retinoic acid-responsive enhancer element in the $5^{\prime}$ flanking region of human MSX1[64]. Functional in vivo evidence was later provided by Chen et al [65] who showed that endogenous retinoids control the spatial expression of Msx 1 by delimiting its expression to the posterior regions of quail embryos at the gastrulation and neurulation stages. Thus retinoids are important regulators of normal Msxl expression in avians. In contrast, in murine embryonic palate mesenchymal cells, retinoic acid appeared to inhibit Msxl expression[66]. In addition, the 5' upstream region of murine Msxl was characterized as having multiple enhancer elements including three potential NFkB-binding sites and an Msx 1 consensus binding site[67-71]. These studies indicate multiple regulations of $M s x 1$ expression.

Blin-Wakkach et al[72] reported the presence of endogenous Msxl antisense RNA in mice, rats and humans. It was suggested that the proportion of the sense and antisense transcripts determines the amount of functional protein available. Upregulation of the antisense RNA appears permissive for the differentiation of craniofacial structures, specially those associated with 
mineralized matrices, while the sense form maintains the cells in a proliferating state[72].

Membraneous bone and cranial suture development rely upon growth factor signals transduced by Msx genes $[11,73,74]$. In vitro assays indicate that suture patency is controlled by the differential regulation of $M s x$ genes by growth factors[74]. It was demonstrated that exogenous addition of FGF4 to the suture mesenchyme or the osteogenic front stimulates mesenchymal Msx I expression and cell proliferation, which promotes suture closure. In similar assays, application of BMP4 could induce both Msx 1 and Msx 2 in the suture mesenchyme resulting in a concomitant increase in tissue thickness. It is proposed that the BMP4-Msx signaling pathway regulates the balance between committed and uncommitted osteogenic cells in the suture. In addition to the regulation by BMPs via direct effect of Smad4 on the $M s x 2$ promoter, Msx 2 expression is also activated by a bi-functional zinc finger protein $\mathrm{YY} 1$ independent of BMP signaling pathway[75, 76].

The branchial arches are largely populated by cranial neural crest cells that migrate from the midbrain-hindbrain regions. The streams of neural crest cells exiting the dorsal aspects of the hindbrain are sculpted through apoptotic elimination of crest cells originating in rhombomeres 3 and 5[22, 78-80]. This apoptotic removal of the neural crest cells is mediated by BMP4-induced $M s \times 2$ expression only in odd-numbered rhombomeres [81].

In the developing face, complimentary expression of Msxl and Barxl in the mandibular mesenchyme specifies patterning events including tooth formation[82, 83]. Also, the overlapping expression of $M s x$ and $D l x$ genes together with the evidence that members of the two families form heterodimers in vitro reveals a putative mechanism for controlling facial patterning events in vivo $[55,84]$. In the mandibular arch of chick embryos Msx 1 expression correlates with areas of cell proliferation while Msx2 shows localization to regions either marked for programmed cell death or specified towards the formation of nonchondrogenic tissues[21]. The mesial localization of Msx 1 in the chick mandibular arch can be reconciled with a role in promoting mandibular arch outgrowth by extrapolation from the truncated mandibular arch phenotype reported in Msxl mutant mice. Further studies in the chick demonstrate that the expanded induction of $M s x$ genes by ectopic application of BMP4 or BMP2 results in bifurcation of the facial skeleton and increased proliferation in the mandibular primordia[85].

In mice, $M s x 1$ is expressed downstream of $d H A N D$, a mesenchymal transcription factor in the Endothelin-1 signaling pathway[86]. Msx 1, Msx 2 and the bHLH transcription factor $d H A N D$ are expressed in an overlapping fashion in the distal mesenchyme of the branchial arches. In $d H A N D$-null embryos Msx 1 expression is lost and the branchial arches become hypoplastic. Msx2 expression remains unaltered in these mutants. Upon detailed examination of this phenotype it was concluded that Msxl is essential for the development of neural crestderived mesenchyme of the branchial arches[86].

Msxl is common to multiple growth factor signaling pathways and serves in the orchestration of inductive events essential to organogenesis. Therefore, we find its repeated use in the BMP, FGF, Endothelin and $\mathrm{SHH}$ signaling pathways. BMP2, BMP4, FGF2, FGF4, FGF8, and FGF9 represent growth factors from the oral and/or the dental epithelia that are capable of inducing Msx 1 expression in the subjacent mesenchyme of the mandible and maxilla[87, 88]. The mesenchymal expression of several growth and transcription factors, namely, Bmp4, Fgf3, Dlx2, syndecan-1, and Ptc in turn show dependence on Msxl expression[87, 89-91].

Between E9.5 and E13.5 Msxl shows a broad distribution distally, overlapping the presumptive incisor regions, in the mandible and maxilla. Subsequently Msx 1 expression becomes localized to the condensing mesenchyme of both the molar and incisor tooth germs. Curiously this shift in Msxl expression is preceded by a shift in Bmp4 expression pattern[92]. Studies show that Msx 1 and Bmp 4 are induced in the dental mesenchyme by epithelial $B m p 4[87,89]$. Once induced a positive feedback loop comes into play between $M s x 1$ and Bmp4 in the dental mesenchyme maintaining the levels of both genes throughout tooth morphogenesis[47, 89, 92]. This same mechanism accounts for the spatial restriction of Msxl expression around late bud stage to the ondontogenic mesenchyme[92]. Thus, Msxl acts epistatic to mesenchymal Bmp4, a candidate factor that signals back to the dental epithelium allowing tooth morphogenesis to proceed to the cap stage[89,93]. Msxl is also required in the $F g f 8$ signaling pathway for the induction of $F g f 3$ in the dental mesenchyme[90]. The two pathways appear to be independent of each other and occur in parallel during early odontogenesis. While BMPs can induce both $M s x 1$ and Msx2 in dental mesenchyme, FGFs can only induce $M s x 1[87,88,90]$. In vitro experiments sug- 
gest that Msx 1 and Msx 2 mediate the inductive effects of BMP7 on mandibular morphogenesis as well as the initiation phase of odontogenesis[94]. The induction of Ptc, a downstream target of Shh signaling, in the dental mesenchyme is contingent upon Msx 1, which is coexpressed with Ptc[91]. Conditional ablation of Shh specifically in the dental epithelium does not alter $M s x 1$ or Msx 2 expression. This proves that Msx 1 and $M s x 2$ are not targets of Shh signaling.

In conclusion, there appears to be multiple levels of regulation of $M s x$ expression at the level of transcription, translation, and protein function, which contribute to the normal patterning and morphogenesis of the face.

\section{Mutations in Msxl cause tooth agenesis and cleft palate}

In human, mutations in the $M S X 1$ gene cause orofacial clefting and tooth agenesis[95-101]. The homeodomain of $M S X 1$ is pivotal in mediating its multiple functions such as DNA-binding, protein-protein interactions, protein stability, and transcription repression. A missense mutation resulting in an arginine to proline substitution within the homeodomain of MSX1 causes selective tooth agenesis in humans, an autosomal dominant phenotype affecting the second premolars and third molars of the secondary dentition[95]. Biochemical and functional analyses of the mutant protein established haploinsufficiency of $M S X 1$ as the molecular basis underlying this phenotype[102]. The mutant protein exhibited reduced stability as a result of structural perturbations and failed to interact with DNA or its cognate protein factors. Accordingly its ability to function as a transcriptional repressor was greatly impaired. The increased sensitivity to $M S X 1$ gene dosage appears to be specific to humans. Curiously, in mice although a null mutation in the Msxl gene resulted in a complete failure of tooth development, mice heterozygous for Msx 1 did not present with any tooth abnormalities[103, 104] (see below). Despite the different phenotypes exhibited by different dosages of Msxl in humans and mice, its importance in tooth morphogenesis remains undisputed.

Wolf-Hirschhorn syndrome (WHS) is a congenital human syndrome results from a deletion of the MSX1 locus on chromosome 4[105]. Phenotypic manifestations of this syndrome featuring midline fusion defects, ear defects, supernumerary teeth, and microcephaly involve regions that express $M S X 1$ in the mouse embryo[18, 19, 106, 107]. Furthermore, a nonsense mutation in MSXI accounts for the genetic etiology of Witkop syndrome characterized by tooth agenesis and nail dysgenesis[100].

In contrast to the haploinsufficiency of $M S X 1$ in human [102], genetically engineered Msx 1 heterozygous mutation in mice does not result in any visible phenotypes $[103,104]$. However, mice carrying Msx 1 null mutation die right after birth, and exhibit severe craniofacial abnormalities[103, 104]. These phenotypes include cleft palate, an absence of alveolar processes, and an arrest of tooth development at the bud stage, thus mimicking the phenotype observed in humans carrying MSX1 mutations.

In the mouse Msxl mutants the dental mesenchyme fails to condense around the dental epithelial buds causing a bud stage arrest of molar tooth germs[103]. Msx 1deficiency leads to significantly reduced expression of Bmp4 in the dental mesenchyme of arrested tooth germs [89]. Gene expression studies also indicate that $M s \times I^{-1}$ - embryos show ablation of $F g f 3$ expression and downregulation of Lef1, Ptc, Dlx2, and syndecan-1 expression in the dental mesenchyme[89, 90, 91]. On the other hand, tenascin expression is unchanged in these mutants. A non-cell autonomous secondary effect of Msxl deficiency is the loss of Shh and Bmp2 expression in the dental epithelium[93]. The bud stage arrest is lifted upon the addition of exogenous BMP4 or by trangenic expression of Bmp4 thereby bypassing the need for $M s x 1$ function [89, 93, 108]. As a result, tooth development proceeded past cap stage in vitro engendering a near complete rescue in kidney capsule cultures and a restoration of alveolar bone formation in transgenic mice [89, 108, 109]. Analysis of gene expression showed that Lef1, Dlx2, Shh and Bmp2 expression is restored following ectopic or exogenous BMP-4 expression. Thus, Msx l-dependent mesenchymal expression of Bmp4 is critical for tooth morphogenesis and alveolar bone formation. An accompanying defect in proliferation observed in Msxl-deficient embryos is attributed to a separate pathway involving FGFs where Msx 1 mediates the induction of $F g f 3$ and syndecan-1, a low-affinity FGF receptor[89, 90]. Bei et al[109] using tissue recombination established that $M s x l$ imparts early and late functions to tooth development. In the early phase it acts epistatic to Bmp4 in the bud stage dental mesenchyme. The Msxl-induced Bmp4 from the dental mesenchyme instructs the overlying dental epithelium to form the enamel knot, which guides tooth morphogenesis $[93,110]$. After the cap stage, tooth development be- 
comes independent of $M s x l$ function. During the later cyto-differentiation stage $M s x 1$ maintains the survival of odontoblasts and the dental pulp[109].

In humans and mice loss of Msx 1 function results in non-syndromic clefts of the secondary palate and tooth agenesis[95, 97, 103, 104]. Until recently, there has been much speculation surrounding the role of Msxl in palate development. It was previously believed that the cleft secondary palate observed in Msx I-deficient mice occurs as a consequence of a primary defect in tooth development $[18,19,103]$. This contention was disproved recently by functional assays using a transgenic mouse model where the Msxl promoter directs the expression of human Bmp4 in developing tooth and palate in the $\mathrm{MsxI}^{-}$ - background leading to rescue of neonatal lethality in some mice[62, 93, 108]. Notably, all of the surviving $M s \times 1^{-1-} / T g$ mice exhibited a closed palate although they still lacked teeth. Thus, the transgene could specifically rescue the cleft palate phenotype independent of the tooth phenotype.

Msxl is expressed in the anterior mesenchyme of the developing palate from E11.5 to E13.5. The posterior regions of the developing palate do not express $M s x 1$. The expression of Msxl in the palatal mesenchyme is weak relative to its expression in the dental mesenchyme [62]. In the Msx I null mutant embryos the paired palatal shelves elevate normally but fail to make contact and fuse[103]. This failed fusion between the palatal shelves of $M s \times 1^{1-}$ embryos is the result of significantly lower levels of cell proliferation in their anterior region leading to growth impairment[62]. Examination of gene expression levels revealed significant downregulation of Bmp 4 levels in the palatal mesenchyme, Shh in the medial edge epithelium and Bmp2 in both the epithelium and mesenchyme of E13.5 Msxl mutant embryos. Following transgenic rescue of the cleft palate the gene expression and proliferation levels in the anterior palate are restored to normalcy. Bead implantation experiments indicate that $M s x 1$ directly regulates $B m p 4$ expression while its effects on $S h$, Bmp2 and mitogenesis are indirect. Thus, through its regulation of specific growth factor expression Msx 1 maintains growth of the anterior palate during mammalian palatogenesis.

\section{Middle ear defects in Msx1-deficient mice}

Msxl-deficient mice show anomalous development of the malleus, one of the three middle ear ossicles[103]. The malleus is shorter than in wild types and it consti- tuent part, the processus brevis is absent in these null mutants. The gross morphology of the remaining middle ear ossicles, the incus and the stapes appears normal. Similar to the tooth germs, the malleal primordia in the mutant embryo show reduced expression of Bmp4[111]. The transgenic expression of Bmp4 in the Msx 1 mutant background failed to affect a rescue and the surviving mice still lacked the processus brevis, which allows the measurement of auditory evoked potentials to assess the functional significance of the malleal processus brevis. It was demonstrated that the malleal processus brevis is dispensable for sound transmission and balance in mice [111].

\section{Craniofacial defects associated with Msx2 mutations}

Role of Msx 2 in craniofacial development was initially revealed by a mutation in the MSX2 gene causing Bostontype craniosynostosis in humans[112]. Boston-type craniosynostosis is characterized by the premature fusion of skull bones together with certain orofacial bone abnormalities. This mutation in the homeodomain of the MSX2 protein increased its DNA binding affinity and was believed to represent a gain-of-function mutation[6, 112]. Conversely, haploinsufficiency of $M S X 2$ causes midline cranial defects reflected in the occurrence of wide-open fontanels in the skull vault[113]. Thus MSX2 function is required for normal skull and suture morphogenesis.

A species-specific dependence on MSX2 dosage was established variously through knock-out strategies, transgene expression and mutation studies. While haploinsufficiency in human $M S X 2$ results in parietal foramina the $M s x 2$ heterozygous mice manifest no abnormal phenotype[113, 114]. In contrast, Msx 2 homozygous null mice have a calvarial foramen similar to humans with MSX2 haploinsufficiency[114]. Liu et al [115] showed that mice carrying a missence mutation within the Msx2 homoeodomain developed craniosynostosis similar to mice that overexpress the wild type allele. Again trangenic mice expressing human MSX2 exhibit multiple craniofacial defects including exencephaly[116].

Several studies have been undertaken to divulge the molecular mechanism and pathophysiology of Bostontype craniosynostosis. Essentially a proline to histidine substitution at position 7 of the homeodomain of Msx2 
missense mutation increases the binding affinity of Msx2 for its target DNA without altering the binding site specificity while increasing the Msx2-DNA complex stability $[6,117]$. The outcome is an augmentation of the normal function of Msx2. Overexpression and misexpression of Msx 2 transgene in mice gave a similar phenotype registering pronounced growth of the calvarial bones and an increased number of proliferating osteoblasts at the osteogenic front $[115,118]$.

In a normal developing cranium, $M s x 2$ is required to maintain a proliferating population of osteoblast progenitors at the osteogenic front[118]. Functional studies show that overexpression of Msx2 impedes osteoblast differentiation while antisense inhibition promotes differentiation[119]. The reduction in the length of the axial and appendicular skeleton in Msx2 null mice lends credence to its role in regulating the proliferation of bone-forming cells[120].

The temporal and spatial expression of Msx2 in the suture mesenchyme and dura matter prior to birth appears to correlate with its role in the regulation of suture patency during prenatal development. The widespread occurrence of BMP4 in the developing suture as well as its ability to induce both $M s x 1$ and $M s x 2$ in the suture in vitro has been demonstrated[74]. Furthermore, genes typically expressed in terminally differentiated osteoblasts such as collagen-I and osteocalcin were shown to be regulated by Msx2[54, 121, 122, 123]. These data suggest that the modulation of $M s x$ genes by BMPs and other factors in the developing suture regulates the rate of differentiation of the osteoblasts at the advancing osteogenic fronts and thereby calvarial osteogenesis. Collectively, the evidence that both gain- and loss-offunction mutations in $M s x 2$ cause craniofacial defects indicates that the precise regulation of $M s \times 2$ expression and optimal level of Msx 2 protein are crucial for normal development of craniofacial organs.

\section{Msx1 and Msx2 function redundantly in craniofacial development}

Several biochemical, expression, and knockout studies suggest that $M s x 1$ and $M s \times 2$ are functionally redundant. Investigations at the biochemical level reveal that MSX1 and MSX2 have common DNA-binding and transcriptional properties [48]. They both recognize the same DNA consensus site and function as transcriptional repressors. Further, structural comparisons reveal that Msx 1 and Msx 2 only differ in one amino acid in their ho- meodomains. Spatial and temporal expressions of Msx 1 and $M s x 2$ in mice show a certain degree of co-localization. Consistent with this co-localization pattern, $M s \times 1 / M s x 2$ double mutant mice exhibit synergistic defects in calvarial, tooth, ear, limb, hair follicle, and mammary gland development $[90,111,114]$. Therefore, while the $M s x 2$ single mutant mice show either incomplete or delayed ossification of the calvarial bones resulting in calvarial patency, the double mutant mice are deficient in calvarial ossification. With respect to tooth, hair follicle and mammary gland development $M s x 1$ and $M s x 2$ show functional redundancy through the early stages of organogenesis, coinciding with their overlapping expression pattern. However, the participation of $M s \times 2$ in the early stages of tooth development appears nonessential since mice heterozygous for $M s x 1$ but lacking functional $M s \times 2$ do not exhibit early tooth defects[90]. Tooth development proceeds normally through the lamina, bud, and cap stages in the Msx2-deficient mice. A requirement for Msx2 in tooth development is seen in the late stages of organogenesis following the downregulation of $M s x 1$ expression. Anomalous tooth development in the Msx2-deficient mice becomes evident at E16.5 when the stellate reticulum and stratum intermedium fail to develop normally resulting in the degeneration of the ameloblast and ultimately the enamel organ. It is postulated that $M s x 2$ participates in the regulation of the spatiotemporal expression of the amelogenin gene during tooth development [124]. In the absence of Msxl, the phenotype of $M s x 2$ mutant mice is greatly amplified. Molar tooth development arrests at the dental lamina stage in $M s x 1 / M s x 2$ compound mutants unlike $M s x I^{-/-}$ mice that exhibit a bud-stage arrest $[90,103]$. Thus, at the tooth initiation stages $M s x l$ and transiently expressed Msx 2 function redundantly. Similarly additive hypomorphism is observed in the developing middle ear of compound Msx mutants. While $M s \times 1^{-/-}$mice lack the processus brevis, mice double null for $M s x 1$ and $M s \times 2$ genes are lacking the manubrium as well as the processus brevis. In the $M s \times 1 / M s x 2$ double mutant mice there is a failure in hair follicle induction unlike $M s x 2^{-/-}$mice where the pelage hairs form but are lost prematurely owing to defects in hair maintenance[114, 125]. Similarly, in the absence of Msx 1 and Msx 2 the mammary gland epithelium does not invaginate while a loss of $M s x 2$ alone results in a sprout stage arrest of the mammary gland. Therefore in the tooth, hair and mammary gland, a loss of Msx 1 and Msx2 results in a more severe phenotype 
than those resulting from the loss of any one. Functional redundancy between $M s x 1$ and Msx 2 is also evident from limb deformities that are manifested by double knockout mice[126]. Accordingly, in a single mutant background the limbs develop normally, however, mice that are null for both $M s x 1$ and Msx2 develop limbs with lack of antero-posterior polarity, absence of radius, marked inhibition of apoptosis in the interdigital regions, and polydactyly[127]. Taken together, these expression and functional analysis data support the hypothesis that functional redundancy exists between the $M s x$ genes.

\section{CONCLUSION}

Members of the Msx homeobox gene family are among the critical factors involved in craniofacial development. These regulatory proteins function as transcriptional repressors and are involved in the modulation of craniofacial, limb and nervous system development. Of the three members, Msx 1 and Msx 2 have been given special consideration in this discussion because of their incontrovertible relevance to craniofacial morphogenesis. Loss-of-function and gain-of-function studies show that in mice as in humans Msx 1 and Msx 2 are required for normal craniofacial morphogenesis. Although there is a species-specific difference in the dosage requirements of Msx genes in humans and mice, both show similar phenotypes. Lastly we have considered the functional redundancy between $M s x 1$ and $M s x 2$ by comparisons of single, double, and compound mutant phenotypes which gives greater hypormorphism in organs where there is overlapping expression of the $M s x$ genes. In summary, recent advances have revealed important roles for $M s x$ genes in embryogenesis as well as the functional properties of Msx proteins. It would be of great interest to identify the direct downstream target genes of Msx proteins in vivo and their associated cellular processes including proliferation, apoptosis, cell adhesion and migration during organogenesis.

\section{ACKNOWLEDGEMENTS}

The studies described here from the authors' laboratory were supported by the NIH grants (R01DE12329, R01DE14044, P60DE13076), the National Science Foundation grant(IBN-9796321), and the Millenium Trust Health Excellence Fund (HEF-2000-05-04) from the Louisiana Board of Regents.

\section{REFERENCES}

1 Francis-West PH, Robson L, Evans DJR. Craniofacial Development: The tissue and molecular interactions that control development of the head. In: Beck F, Kriz W, Marani E, Sano Y, Schoenwolf GC, Zilles K. Eds. Advances in Anatomy Embryology and Cell Biology. Springer-Verlag: New York 2003.

2 Mooney MP, Siegel MI, eds. Understanding craniofacial anomalies: The etiopathogenesis of craniosynostoses and facial clefting. New York: Wiley-Liss, 2002

3 Hill RE, Jones PF, Rees AR, et al. A new family of mouse homeo box-containing genes: molecular structure, chromosomal location, and developmental expression of Hox-7.1. Genes Dev 1989; 3 : 26-37.

4 Robert B, Sassoon D, Jacq B, Gehring W, Buckingham M. Hox7, a mouse homeobox gene with a novel pattern of expression during embryogenesis. EMBO J 1989; 8:91-100.

5 Holland PWH. Cloning and evolutionary analysis of msh-like homeobox genes from mouse, zebrafish and ascidian. Gene 1991; 98:253-7.

6 Ma L, Golden S, Wu L, Maxson R. The molecular basis of Boston-type craniosynostosis: the Pro148 $\rightarrow$ His mutation in the N-terminal arm of the MSX2 homeodomain stabilizes DNA binding without altering nucleotide sequence preferences. Hum Mol Genet 1996; 5:1915-20.

7 Dobias SL, Ma L, Wu H, Bell JR, Maxson R. The evolution of Msx gene function: expression and regulation of a sea urchin Msx class homeobox gene. Mech Dev 1997; 61:37-48.

8 Akimenko MA, Johnson SL, Westerfield M, Ekker M. Differential induction of four msx homeobox genes during fin development and regeneration in zebrafish. Development 1995; 121:347-57.

9 Su MW, Suzuki HR, Solursh M, Ramirez F. Progressively restricted expression of a new homeobox-containing gene during Xenopus laevis embryogenesis. Development 1991; 111:117987.

10 Coelho CND, Sumoy L, Rodgers BJ, et al. Expression of the chicken homeobox-containing gene GHox-8 during embryonic chick limb development. Mech Dev 1991; 34:143-54.

11 Takahashi Y, Le Douarin N. cDNA cloning of a quail homeobox gene and its expression in neural crest-derived mesenchyme and lateral plate mesoderm. Proc Natl Acad Sci USA 1990; 87:74826.

12 Suzuki HR, Padanilam BJ, Vitale E, Ramirez F, Solursh M. Repeating developmental expression of G-Hox 7, a novel homeobox-containing gene in the chicken. Dev Biol 1991; 148: 375-88.

13 Padanilam BJ, Stadler HS, Mills KA, et al. Characterization of the human HOX 7 cDNA and identification of polymor-phic markers. Hum Mol Genet 1992; 1:407-10.

14 Davidson DR, Hill RE. Msh-like genes: a family of homeo-box genes with wide-ranging expression during vertebrate development. Sem in Dev Biol 1991; 2:405-12.

15 Davidson D. The function and evolution of Msx genes: pointers and paradoxes. Trends Genet 1995; 11:405-11.

16 Shimeld SM, McKay IJ, Sharpe PT. The murine homeobox gene Msx-3 shows highly restricted expression in the deve-loping neural tube. Mech Dev 1996; 55:201-10.

17 Wang W, Chen X, Xu H, Lufkin T. Msx3: a novel murine homo- 
logue of the Drosophila msh homeobox gene restricted to the dorsal embryonic central nervous system. Mech Dev 1996; 58: 203-15.

18 MacKenzie A, Ferguson MW, Sharpe PT. Hox-7 expression during murine craniofacial development. Development 1991a; 113:601-11.

19 Mackenzie A, Leeming GL, Jowett AK, Ferguson MW, Sharpe PT. The homeobox gene Hox 7.1 has specific regional and temporal expression patterns during early murine craniofacial embryogenesis, especially tooth development in vivo and in vitro. Development 1991b; 111:269-85.

20 MacKenzie A, Ferguson MW, Sharpe PT. Expression patterns of the homeobox gene, Hox-8, in the mouse embryo suggest a role in specifying tooth initiation and shape. Development 1992; 115:403-20.

21 Mina M, Gluhak J, Upholt WB, Kollar EJ, Rogers B. Experimental analysis of Msx-1 and Msx-2 gene expression during chick mandibular morphogenesis. Dev Dyn 1995; 202:195-214.

22 Graham A, Koentges G, Lumsden A. Neural crest apoptosis and the establishment of craniofacial pattern: an honorable death. Mol Cell Neurosci 1996; 8:76-83.

23 Shigetani Y, Nobusada Y, Kuratani S. Ectodermally derived FGF8 defines the maxillomandibular region in the early chick embryo: epithelial-mesenchymal interactions in the specification of the craniofacial ectomesenchyme. Dev Biol 2000; 228:73-85.

24 Nichols DH. (1981). Neural crest formation in the head of the mouse embryo as observed using a new histological technique. J Embryol Exp Morphol 1981; 64:105-20.

25 Tan SS, Morriss-Kay GM. Analysis of cranial neural crest cell migration and early fates in postimplantation rat chimaeras. $\mathrm{J}$ Embryol Exp Morphol 1986; 98:21-58.

26 Serbedzija GN, Bronner-Fraser M, Fraser SE. Vital dye analysis of cranial neural crest cell migration in the mouse embryo. Development 1992; 116:297-307.

27 Chai Y, Bringas P, Shuler C, Devaney E, Grosschedl R, Slavkin HC. A mouse mandibular culture model permits the study of neural crest cell migration and tooth development. Int J Dev Biol 1998; 42:87-94.

28 Chai Y, Jiang X, Ito Y, et al. Fate of the mammalian cranial neural crest during tooth and mandibular morphogenesis. Development 2000; 127:1671-9.

29 Hunt P, Clarke JD, Buxton P, Ferretti P, Thorogood P. Segmentation, crest prespecification and the control of facial form. Eur J Oral Sci 1998a; 106 Suppl 1:12-18.

30 Hunt P, Clarke JD, Buxton P, Ferretti P, Thorogood P. Stability and plasticity of neural crest patterning and branchial arch Hox code after extensive cephalic crest rotation. Dev Biol 1998b; 198:82-104.

31 Trainor PA, Ariza-McNaughton L, Krumlauf R. Role of the isthmus and FGFs in resolving the paradox of neural crest plasticity and prepatterning. Science 2002; 295:1288-91.

32 Rijli FM, Mark M, Lakkaraju S, Dierich A, Dolle P, Chambon P. A homeotic transformation is generated in the rostral branchial region of the head by disruption of Hoxa-2, which acts as a selector gene. Cell 1993; 75:1333-49.

33 Bronner-Fraser M. Patterning of the vertebrate neural crest. Perspect Dev Neurobiol 1995; 3:53-62.

34 Sharpe PT. (1995). Homeobox genes and orofacial development. Connect Tissue Res 1995; 32:17-25.
35 Thesleff I, Sharpe P. Signalling networks regulating dental development. Mech Dev 1997; 67:111-23.

36 Anderson DJ, Groves A, Lo L, et al. Cell lineage determination and the control of neuronal identity in the neural crest. Cold Spring Harb Symp Quant Biol 1997; 62:493-504.

37 Saldivar JR, Sechrist JW, Krull CE, Ruffins S, Bronner-Fraser M. Dorsal hindbrain ablation results in rerouting of neural crest migration and changes in gene expression, but normal hyoid development. Development 1997; 124:2729-39.

38 Tucker AS, Sharpe PT. Molecular genetics of tooth morphogenesis and patterning: the right shape in the right place. $\mathrm{J}$ Dent Res 1999; 78:826-34.

39 Diewert VM, Shiota K. Morphological observations in normal primary palate and cleft lip embryos in the Kyoto collection. Teratology 1990; 41:663-77.

40 Wang KY, Juriloff DM, Diewert VM. Deficient and delayed primary palatal fusion and mesenchymal bridge formation in cleft lip-liable strains of mice. J Craniofac Genet Dev Biol 1995; 15:99-116.

41 Sun D, Baur S, Hay ED. Epithelial-mesenchymal transformation is the mechanism for fusion of the craniofacial primordia involved in morphogenesis of the chicken lip. Dev Biol 2000; 228:337-49.

42 Moore KL. and Persaud TVN, eds (1993). Before We Are Born: Essentials of Embryology and Birth Defects. Fourth Edition. Philadelphia. W. B. Saunders, 1993:173-78.

43 Johnston MC, Bronsky PT. Prenatal craniofacial development: new insights on normal and abnormal mechanisms. Crit Rev in Oral Biol Med 1995; 6:368-422.

44 Diewert VM, Wang KY. Recent advances in primary palate and midface morphogenesis research. Crit Rev Oral Biol Med 1992; 4:111-30.

45 Helms JA, Kim CH, Hu D, Minkoff R, Thaller C, Eichele G. Sonic hedgehog participates in craniofacial morphogenesis and is down-regulated by teratogenic doses of retinoic acid. Dev Biol 1997; 187:25-35.

46 Shapira Y, Lubit E, Kuftinec MM, Borell G. The distribution of clefts of the primary and secondary palates by sex, type, and location. Angle Orthodontist 1999; 69:523-8.

47 Chen Y, Maas, R. Signaling loops in the Reciprocal EpithelialMesenchymal Interactions of Mammalian Tooth Development. In: Chuong CM. Eds. Molecular Biology Intelligence Unit 1: Molecular Basis of Epithelial Appendage Morphogenesis. R. G. Landes Company: Austin, Texas 1998:265-82.

48 Catron KM, Wang H, Hu G, Shen, MM, Abate-Shen C. Comparison of MSX-1 and MSX-2 suggests a molecular basis for functional redundancy. Mech Dev 1996; 55:185-99.

49 Bendall AJ, Abate-Shen C. Roles for Msx and Dlx homeo-proteins in vertebrate development. Gene 2000; 247:17-31.

50 Catron KM, Iler N, Abate C. Nucleotides flanking a conserved TAAT core dictate the DNA binding specificity of three murine homeodomain proteins. Mol Cell Biol 1993; 13:2354-65.

51 Catron KM, Zhang H, Marshall SC, Inostroza JA, Wilson JM, Abate C. (1995). Transcriptional repression by Msx-1 does not require homeodomain DNA-binding sites. Mol Cell Biol 1995; 15:861-71.

52 Semenza GL, Wang GL, Kundu R. DNA binding and transcriptional properties of wild-type and mutant forms of the homeodomain protein Msx2. Biochem Biophys Res Commun 
1995; 209:257-62.

53 Zhang H, Catron KM, Abate-Shen C. A role for the Msx-1 homeodomain in transcriptional regulation: residues in the $\mathrm{N}$ terminal arm mediate TATA binding protein interaction and transcriptional repression. Proc Natl Acad Sci USA1996; 93: 1764-9.

54 Newberry EP, Latifi T, Battaile JT, Towler DA. Structurefunction analysis of Msx2-mediated transcriptional suppression. Biochemisty 1997; 36:10451-62.

55 Zhang H, Hu G, Wang H, et al. Heterodimerization of Msx and Dlx homeoproteins results in functional antagonism. Mol Cell Biol 1997; 17:2920-32.

56 Bendall AJ., Rincon-Limas DE, Botas J, Abate-Shen C. Protein complex formation between Msx 1 and Lhx2 homeoproteins is incompatible with DNA binding activity. Differentiation 1998; 63:151-7.

57 Bendall AJ, Ding J, Hu G, Shen MM, Abate-Shen C. Msx1 antagonizes the myogenic activity of $\mathrm{Pax} 3$ in migrating limb muscle precursors. Development 1999; 126:4965-76.

58 Hovde S, Abate-Shen C, Geiger JH. Crystal structure of the Msx-1 homeodomain/DNA complex. Biochemistry 2001; 40: 12013-21.

59 Jowett AK, Vainio S, Ferguson MW, Sharpe PT, Thesleff I. Epithelial-mesenchymal interactions are required for msx 1 and msx 2 gene expression in the developing murine molar tooth. Development 1993; 117:461-70.

60 Yamashiro T, Tummers M, Thesleff I. Expression of bone morphogenetic proteins and $M s x$ genes during root formation. J Dent Res 2003; 82:172-76.

61 Turecková J, Sahlberg C, Aberg T, Ruch JV, Thesleff I, Peterkova R. Comparison of expression of the msx-1, msx-2, BMP-2 and BMP-4 genes in the mouse upper diastemal and molar tooth primordia. Int J Dev Biol 1995; 39:459-68.

62 Zhang Z, Song Y, Zhao X, Zhang X, Fermin C, Chen Y. Rescue of cleft palate in Msx1-deficient mice by transgenic Bmp4 reveals a network of BMP and Shh signaling in the regulation of mammalian palatogenesis. Development 2002; 129: 4135-46.

63 Davideau JL, Demri P, Hotton D, et al. Comparative study of MSX-2, DLX-5, and DLX-7 gene expression during early human tooth development. Pediatr Res 1999; 46: 650-6.

64 Shen R, Chen Y, Huang L, Vitale E, Solursh M. Characterization of the human MSX-1 promoter and an enhancer responsible for retinoic acid induction. Cell Mol Biol Res 1994; 40:297-312.

65 Chen Y, Kostetskii I, Zile MH, Solursh M. Comparative study of Msx-1 expression in early normal and vitamin A-deficient avian embryos. J Exp Zool 1995; 272:299-310.

66 Nugent P, Greene R. Msx-1 gene expression and regulation in embryonic palatal tissue. In Vitro Cell Dev Biol 1998; 34:831-6.

67 Kuzuoka M, Takahashi T, Guron C, Raghow R. Murine homeobox-containing gene, Msx-1: analysis of genomic organization, promoter structure, and potential autoregulatory cis-acting elements. Genomics 1994; 21:85-91.

68 Takahashi T, Guron C, Shetty S, Matsui H, Raghow R. A minimal murine Msx-1 gene promoter. Organization of its cisregulatory motifs and their role in transcriptional activation in cells in culture and in transgenic mice. J Biol Chem 1997; 272: 22667-78.

69 Gonzalez SM, Ferland LH, Robert B, Abdelhay E. Structural and functional analysis of mouse Msx 1 gene promoter: sequence conservation with human MSX1 promoter points at potential regulatory elements. DNA Cell Biol 1998; 17:561-72.

70 Shetty S, Takahashi T, Matsui H, Ayengar R, Raghow R. Transcriptional autorepression of Msx 1 gene is mediated by interactions of Msx 1 protein with a multi-protein trans-criptional complex containing TATA-binding protein, Sp1 and cAMPresponse-element-binding protein-binding protein $(\mathrm{CBP} / \mathrm{p} 300)$. Biochem J 1999; 339:751-8.

71 Mehra-Chaudhary R, Matsui H, Raghow R. Msx3 protein recruits histone deacetylase to down-regulate the Msx 1 promoter. Biochem J 2001; 353:13-22.

72 Blin-Wakkach C, Lezot F, Ghoul-Mazgar S, et al. Endogenous Msx1 antisense transcript: in vivo and in vitro evidences, structure, and potential involvement in skeleton development in mammals. Proc Natl Acad Sci 2001; 98:7336-41.

73 Takahashi Y, Bontoux M, Le Douarin NM. Epitheliomesenchymal interactions are critical for Quox 7 expression and membrane bone differentiation in the neural crest derived mandibular mesenchyme. EMBO J 1991; 10:2387-93.

74 Kim HJ, Rice DP, Kettunen PJ, Thesleff I. FGF-, BMP- and Shh-mediated signalling pathways in the regulation of cranial suture morphogenesis and calvarial bone development. Development 1998; 125:1241-51.

75 Sirard C, Kim S, Mirtsos C, et al. Targeted disruption in murine cells reveals variable requirement for Smad4 in transforming growth factor beta-related signaling. J Biol Chem 2000; 275: 2063-70.

76 Tan DP, Nonaka K, Nucholls GH, et al. YY1 activates Msx2 gene independent of bone morphogenetic protein signaling. Nucl. Acids Res 2002; 30:1213-23.

78 Graham A, Heyman I, Lumsden A. Even-numbered rhombomeres control the apoptotic elimination of neural crest cells from oddnumbered rhombomeres in the chick hindbrain. Development 1993; 119:233-45.

79 Graham A, Francis-West P, Brickell P, Lumsden A. The signalling molecule BMP4 mediates apoptosis in the rhombencephalic neural crest. Nature 1994; 372:684-6.

80 Farlie PG, Kerr R, Thomas $\mathrm{P}$ et al. A paraxial exclusion zone creates patterned cranial neural crest cell outgrowth adjacent to rhombomeres 3 and 5. Dev Biol 1999; 213:70-84.

81 Takahashi K, Nuckolls GH, Tanaka O, et al. Adenovirus-mediated ectopic expression of Msx2 in even-numbered rhombomeres induces apoptotic elimination of cranial neural crest cells in ovo. Development 1998; 125:1627-35.

82 Tucker AS, Matthews KL, Sharpe PT. Transformation of tooth type induced by inhibition of BMP signaling. Science 1998b; 282:1136-8.

83 Barlow AJ, Bogardi JP, Ladher R, Francis-West PH. Expression of chick Barx-1 and its differential regulation by FGF-8 and BMP signaling in the maxillary primordia. Dev Dyn 1999; 214 : 291-302.

84 Francis-West P, Ladher R, Barlow A, Graveson A. Signalling interactions during facial development. Mech Dev 1998; 75:328.

85 Barlow AJ, Francis-West PH. Ectopic application of recombinant BMP-2 and BMP-4 can change patterning of developing chick facial primordia. Development 1997; 124:391-8.

86 Thomas T, Kurihara H, Yamagishi H, et al. A signaling cascade involving endothelin-1, dHAND and msx 1 regulates development gene HOX7 maps to chromosome 4p16.1 and may be implicated 
of neural-crest-derived branchial arch mesenchyme. Development 1998; 125:3005-14.

87 Vainio S, Karavanova I, Jowett A, Thesleff I. Identification of BMP-4 as a signal mediating secondary induction between epithelial and mesenchymal tissues during early tooth development. Cell 1993; 75:45-58.

88 Kettunen P, Thesleff I. Expression and function of FGFs-4, -8, and -9 suggest functional redundancy and repetitive use as epithelial signals during tooth morphogenesis. Dev Dyn 1998; 211:256-68.

89 Chen Y, Bei M, Woo I, Satokata I, Maas R. Msx 1 controls inductive signaling in mammalian tooth morphogenesis. Development 1996; 122:3035-44.

90 Bei M, Maas R. FGFs and BMP4 induce both Msx 1independent and Msx1-dependent signaling pathways in early tooth development. Development - Suppl 1998; 125:4325-33.

91 Zhang Y, Zhao X, Hu Y, et al. Msx1 is required for the induction of Patched by Sonic hedgehog in the mammalian tooth germ. Dev Dyn 1999; 215:45-53.

92 Tucker AS, Al Khamis A, Sharpe PT. Interactions between Bmp-4 and Msx-1 act to restrict gene expression to odontogenic mesenchyme. Dev Dyn 1998a; 212:533-9.

93 Zhang Y, Zhang Z, Zhao X, et al. A new function of BMP4: dual role for BMP4 in regulation of Sonic hedgehog expression in the mouse tooth germ. Development 2000; 127:1431-43.

94 Wang YH, Rutherford B, Upholt WB, Mina M. Effects of BMP7 on mouse tooth mesenchyme and chick mandibular mesenchyme. Dev Dyn 1999; 216:320-35.

95 Vastardis H, Karimbux N, Guthua SW, Seidman JG, Seidman CE. A human MSX1 homeodomain missense mutation causes selective tooth agenesis. Nat Genet 1996; 13:417-21.

96 Lidral AC, Romitti PA, Basart AM, et al. Association of MSX1 and TGFB3 with nonsyndromic clefting in humans. Am J Hum Genet 1998; 63:557-68.

97 van den Boogaard MJ, Dorland M, Beemer FA, van Amstel HK. MSX1 mutation is associated with orofacial clefting and tooth agenesis in humans. Nat Genet 2000; 24:342-3.

98 Beaty TH, Wang H, Hetmanski JB, et al. A case-control study of nonsyndromic oral clefts in Maryland. Ann Epidemiol 2001; 11: 434-42.

99 Blanco R, Chakraborty R, Barton SA et al. Evidence of a sexdependent association between the MSX1 locus and nonsyndromic cleft lip with or without cleft palate in the Chilean population. Hum Biol 2001; 73:81-9.

100 Jumlongras D, Bei M, Stimson JM, et al. A nonsense mutation in MSX1 causes Witkop syndrome. Am J Hum Genet 2001; 69: 67-74.

101 Lidral AC, Reising BC. The role of MSX1 in human tooth agenesis. J Dent Res 2002; 81:274-8.

$102 \mathrm{Hu} \mathrm{G}$, Vastardis H, Bendall AJ, et al. Haploinsufficiency of MSX1: a mechanism for selective tooth agenesis. Mol Cell Biol 1998; 18:6044-51.

103 Satokata I, Maas R. Msx1 deficient mice exhibit cleft palate and abnormalities of craniofacial and tooth development. Nat Genet 1994; 6:348-56.

104 Houzelstein D, Cohen A, Buckingham ME, Robert B. Insertional mutation of the mouse Msx 1 homeobox gene by an nlacZ reporter gene. Mech Dev 1997; 65:123-33.

105 Ivens A, Flavin N, Williamson R, et al. The human homeobox in Wolf-Hirschhorn syndrome. Hum Genet 1990; 84:473-6.

106 Lurie IW, Lazjuk GI, Ussova EB, Presman EB, Gurevich DB. The Wolf-Hirschhorne syndrome. Clin Genet 1989; 17:375-84.

107 Fujimoto A, Wilson MC. Growth retardation in Wolf-Hirschhorn syndrome. Hum. Genet 1990; 84:296-7.

108 Zhao X, Zhang Z, Song Y, et al. Transgenically ectopic expression of Bmp4 to the Msx1 mutant dental mesenchyme restores downstream gene expression but represses Shh and Bmp2 in the enamel knot of wild type tooth germ. Mech Dev 2000; 99: 29-38.

109 Bei M, Kratochwil K, Maas RL. BMP4 rescues a non-cellautonomous function of Msx 1 in tooth development. Development 2000; 127:4711-8.

110 Jernvall J, Aberg T, Kettunen P, Keranen S, Thesleff I. The life history of an embryonic signaling center: BMP-4 induces p21 and is associated with apoptosis in the mouse tooth enamel knot. Development 1998; 125:161-9.

111 Zhang Z, Zhang X, Avniel WA, et al. Malleal processus brevis is dispensable for normal hearing in mice. Dev Dyn 2003; 227: 69-77.

112 Jabs EW, Muller U, Li X, et al. A mutation in the homeodomain of the human MSX2 gene in a family affected with autosomal dominant craniosynostosis. Cell 1993; 75:443-50.

113 Wilkie AO, Tang Z, Elanko N, et al. Functional haploinsufficiency of the human homeobox gene MSX2 causes defects in skull ossification. Nat Genet 2000; 24:387-90.

114 Satokata I, Ma L, Ohshima H, et al. Msx2 deficiency in mice causes pleiotropic defects in bone growth and ectodermal organ formation. Nat Genet 2000; 24:391-5.

115 Liu YH, Kundu R, Wu L, et al. Premature suture closure and ectopic cranial bone in mice expressing Msx2 transgenes in the developing skull. Proc Natl Acad Sci USA 1995; 92:6137-41.

116 Winograd J, Reilly MP, Roe R, et al. Perinatal lethality and multiple craniofacial malformations in MSX2 transgenic mice. Hum Mol Genet 1997; 6:369-79.

$117 \mathrm{Wu} \mathrm{L}, \mathrm{Wu} \mathrm{H}, \mathrm{Ma} \mathrm{L}$, et al. Miz1, a novel zinc finger transcription factor that interacts with Msx2 and enhances its affinity for DNA. Mech Dev 1997; 65:3-17. erratum in Mech Dev 1997; 69:219.

118 Liu YH, Tang Z, Kundu RK, et al. Msx2 gene dosage influences the number of proliferative osteogenic cells in growth centers of the developing murine skull: a possible mechanism for MSX2mediated craniosynostosis in humans. Dev Biol 1999; 205:26074.

119 Dodig M, Tadic T, Kronenberg MS, et al. Ectopic Msx2 overexpression inhibits and Msx2 antisense stimulates calvarial osteoblast differentiation. Dev Biol 1999; 209:298-307.

120 Ferguson MWJ. A hole in the head. Nat Genet 2000; 24:330-1.

121 Towler DA, Rutledge SJ, Rodan GA. Msx-2/Hox 8.1: a transcriptional regulator of the rat osteocalcin promoter. Mol Endocrinol 1994; 8:1484-93.

122 Dodig M, Kronenberg MS, Bedalov A, et al. Identification of a TAAT-containing motif required for high level expression of the COL1A1 promoter in differentiated osteoblasts of transgenic mice. J Biol Chem 1996; 271:16422-9.

123 Hoffmann HM, Beumer TL, Rahman S, et al. Bone tissuespecific transcription of the osteocalcin gene: role of an activator osteoblast-specific complex and suppressor hox proteins that 
bind the OC box. J Cell Biochem 1996; 61:310-24

124 Zhou YL, Lei Y, Snead ML. Functional antagonism between Msx2 and CCAAT/Enhancer-binding protein aá in regulating the mouse amelogenin gene expression is mediated by proteinprotein interaction. J Biol Chem 2000; 275:29066-75.

$125 \mathrm{Ma} \mathrm{L}$, Liu J, Wu T, et al. 'Cyclic alopecia' in Msx2 mutants: defects in hair cycling and hair shaft differentiation. Development
2003; 130:379-89.

126 Chen Y, Zhao X. Shaping limbs by apoptosis. J Exp Zool 1998; 282:691-702.

127 Chen Y, Satokata I, Heaney S, Woo I, Maas R. Control of limb bud pattern formation and apoptosis by mouse Msx genes. Dev Biol 1997; 186:349. 